\title{
Modified Biomass for Pollution Cleaning Under the Frames of Biorefinery and Sustainable Circular Bioeconomy
}

\author{
Dimitrios Sidiras \\ Lab. Simulation of Industrial Processes, Dep. Industrial Management and Technology, University of Piraeus \\ 80 Karaoli \& Dimitriou, GR 18534 Piraeus, Greece \\ sidiras@unipi.gr
}

\begin{abstract}
The issues of global population growth, dwindling fossil fuel resources and the ever-advancing climate change show the need for the establishment of an alternative biobased economy. The biorefinery concept is the centre of a bio-based economy, and promising largely waste-free use of biomass, efficient conversion routes, and pathways for the production of energy, biofuels and numerous value added natural products such as natural fine chemicals, polymers, fuels etc. An integrated biorefinery will play an important role in a future bio-economy providing its economic feasibility and socio-environmental sustainability. Multi-product/service biomass processing systems, consisting of sequences including: feedstock handling and storage, pre-treatment (physical, chemical, biological), fractionation to main and co-products, product and co-product upgrading, product \& co-product marketing, integrated material /energy /economic flows. Biorefineries are one of the pillars of sustainability as long as they preserve the bioremediation of degraded land and poor crop production i.e. exploitation of coastal wastes. Furthermore, the biorefineries' processing tends to be a zero waste process through the holistic use of renewable resources following the green chemistry principles. Moreover, the biorefineries show a multi-level (industrial and social) profitability producing high value added products, creating employment, supporting by national and European funds. In the frames of biorefining, nowadays there is a worldwide resurgence of interest in the exploitation of marine derived biomass, in the frame of the overall return to the natural resources. This trend is based firstly on the fossil fuel depletion and secondly on the increasing public awareness of the environmental and health hazards related to chemical product. Modified biomass can be widely used for pollution cleaning (as in the case of oil spills) under the frames of biorefinery and sustainable circular bioeconomy.
\end{abstract}

Keywords: Biomass, Biorefinery, Bioeconomy, Lignocellulosic, Modification, Sustainable, Pollution, Adsorption.

\section{Introduction}

The combustion of fossil/non-renewable fuels (coal, oil, natural gas) for the conventional producing of transportation fuels, chemicals, and power, has been established for many decades. This method is a significant global concern as it releases greenhouse gases, mainly carbon dioxide, into the atmosphere [1]. The European Commission has set a long-term goal to develop a competitive, resource efficient and low carbon economy by 2050 . Bioeconomy is expected to play an important role in the low carbon economy. Scarlat et al. [2] provided a review of the policy framework for developing a bioeconomy in the European Union covering energy, climate, agriculture, forestry, industry and research. The EU has a number of wellestablished traditional bio-based industries, ranging from agriculture, food, feed, fibre and forest-based industries. The onset of formulating strategies and policies regarding the bioeconomy can be attributed to the publication of the policy agenda on the bioeconomy by the Organisation for Economic Cooperation and Development in 2009 [3]. As part of a green economy, the bio-based economy plays a key role, being able to replace fossil fuels on a large scale, not only for energy applications, but also for chemicals and materials applications. The bio-based economy integrates the full range of natural and renewable biological resources (land resources, sea resources, biodiversity and biological materials) and biological processes. Consequently, a bio-based economy is not new, while before the industrial revolution, economies were mainly bio-based. Biomass is already used as feedstock (e.g., wood based materials, pulp and paper production, biomass-derived fibres), and as biofuel feedstock (oil crops, starch, sugar crops). The transition toward a modern bio-based economy implies challenges such as the sustainability of biomass raw material, efficiency in biomass use and economy of scales in biomass deployment [2]. Establishment of a bio-based economy has been recognised as one of the key issues for sustainable development. In the future, renewable resources will play a key role as carbon dioxide neutral raw material for sustainable industrial production 
to control depletion of fossil resources. Options to fully exploit the potential of renewable resources as industrial chemical feedstock imply different routes [4].

A great fraction of worldwide energy carriers and material products come from fossil fuel refinery. Because of the ongoing price increase of fossil resources, their uncertain availability, and their environmental concerns, the feasibility of oil exploitation is predicted to decrease in the near future. Consequently, alternative solutions able to moderate climate change and reduce the consumption of fossil fuels should be promoted. The replacement of oil with biomass as raw material for fuel and chemical production is an interesting option and is the driving force for the development of biorefinery complexes. In biorefinery, almost all the types of biomass feedstocks can be converted to different classes of biofuels and biochemicals through jointly applied conversion technologies. Cherubini [5] provided a description of the biorefinery concept, in comparison with the current oil refinery. The focus is on the state of the art in biofuel and biochemical production, as well as discussion of the most important biomass feedstocks, conversion technologies and final products. Through the integration of green chemistry into biorefineries, and the use of low environmental impact technologies, future sustainable production chains of biofuels and high value chemicals from biomass can be established. The aim of the bio-industry is to be competitive in the market and lead to the progressive replacement of oil refinery products.

The production of bioethanol, biohydrogen and biogas from straw has been extensively investigated within a biorefinery framework. Straw can be hydrothermally liberated to a cellulose rich solid fibre fraction and a hemicellulose rich liquid fraction. Enzymatic hydrolysis followed by fermentation of cellulose yields ethanol, while dark fermentation of liquid phase/hydrolysate produces hydrogen. The effluents from both bioethanol and biohydrogen processes can be further used to produce methane. Moreover, evaluation of different straw-to-biofuel production scenarios showed that either use of straw for biogas production or multi-fuel production were the energetically most efficient processes compared to production of mono-fuel such as bioethanol. Accordingly, multiple biofuels production from straw can increase the efficiency for material and energy and can apparently be more inexpensive process for biomass utilization [6]. Bioconversion of renewable lignocellulosic biomass to biofuel and value added products are internationally gaining significant importance. Market forces demonstrate a drive towards products benign to natural environment increasing the importance of renewable materials. The development of second generation bioethanol from lignocellulosic biomass has many advantages from both energy and environmental point of views. Biomass, an inexpensive feedstock, considered sustainable and renewable, is an option with the potential to replace a wide range of fossil based products within the energy sector (heat, power, fuels, materials and chemicals) [7]. Lignocellulose is a major structural component of woody and non-woody plants and consists of cellulose, hemicellulose and lignin. The effective utilization of all the three components would play a significant role in the economic viability of cellulosic ethanol. Biomass conversion process involves five major steps: (i) choice of suitable biomass, (ii) effective pre-treatment, (ii) production of enzymes (cellulases and hemicellulases), (vi) fermentation of hexoses and pentoses and (v) downstream processing. Within the context of production of biofuels, pre-treatment has come to denote processes by which cellulosic biomass is made amenable to the action of hydrolytic enzymes. The limited effectiveness of current enzymatic process on lignocellulose is thought to be due to the relative difficulties in pre-treating the feedstocks. Menon and Rao [8] gave a comprehensive state of the art describing the (a) advancement in recent pre-treatments, (b) metabolic engineering approaches with special emphasis on the latest developments in consolidated biomass processing, (c) current global scenario of bioethanol pilot plants and (d) biorefinery concept for the production of biofuels and bioproducts.

An ideal renewable resource is one that can be restocked over a relatively short timescale or is essentially limitless in supply. Improved resource utilisation can positively influence the profits of industry as well as enable new companies to start up, produce new growth and expand innovation opportunities by moving towards the ultimate sustainability goal of a zerowaste circular economy. Green chemistry is a movement dedicated to the development of more environmentally caring alternatives to hazardous and wasteful chemical processes as a result of (i) the increased awareness in industry of the costs of waste and (ii) the government regulations requiring cleaner chemical manufacturing. Three different types of biorefinery have been defined in the literature [9-16]:

- Phase I biorefinery (single feedstock, single process and single major product),

- Phase II biorefinery (single feedstock, multiple processes and multiple major products) and

- Phase III biorefinery (multiple feedstocks, multiple processes and multiple major products).

Oil spills are a global concern due to the environmental and economic impact. Various commercial systems have been developed to control these spills, including the use of fibres as sorbents. However, most sorbents end up in landfills or incineration after single use. These options either produce another source of pollution or increase the oil recovery cost. Plant 
biomass is renewable resource that can be converted into useful materials and energy. Barley straw, an agricultural waste, was used as sorbent material [17].

The purpose of this study is to demonstrate that modified lignocellulosic biomass (wood and straw) can be widely used for pollution cleaning (as in the case of oil spills, dyes and heavy metals) under the frames of biorefinery, sustainable circular bioeconomy and industrial ecology.

\section{Materials and Methods \\ 2.1. Materials}

Pine and spruce sawdust as well as barley and wheat straw were used as potential adsorbents. The moisture content of the material was $8-9 \% \mathrm{w} / \mathrm{w}$. After screening, the particle sizes isolated were 1-2 mm for sawdust, $1-2 \mathrm{~cm}$ for straw and 424 $\mathrm{cm}$ for straw scale up $[18,19]$.

\subsection{The modification process}

The sawdust, the wheat straw and the barley straw were pre-treated by (i) autohydrolysis or (ii) acid (sulfuric or maleic) catalysed hydrolysis in a 3.75-L batch reactor PARR 4843 at high temperatures $140-240{ }^{\circ} \mathrm{C}$ [20, 21]. The wheat straw sulfuric acid hydrolysis pre-treatment was performed in a $0.5 \mathrm{~L}$ glass reactor as regards the small particles and in a $20 \mathrm{~L}$ CHEMGLASS glass reactor for the big particles. In the case of the $0.5 \mathrm{~L}$ glass reactor, the acid hydrolysis isothermal time was $0-4 \mathrm{~h}$ (not including the preheating time); the reaction was catalysed by sulfuric acid $0.06-1.8 \mathrm{M}$ at a liquid-to-solid ratio of 10:1; the liquid phase volume (water) was $400 \mathrm{~mL}$ and the solid material dose (wheat straw) was $40 \mathrm{~g}$. The reaction ending temperature was $100{ }^{\circ} \mathrm{C}$ reached after the $40 \mathrm{~min}$ preheating period. In the case of the $20 \mathrm{~L}$ reactor, the acid hydrolysis isothermal time was $4 \mathrm{~h}$ (not including the preheating time); the reaction was catalysed by sulfuric acid $0.45 \mathrm{M}$ at a liquidto-solid ratio of 20:1; the liquid phase volume (water) was $10 \mathrm{~L}$ and the solid material dose (wheat straw) was $500 \mathrm{~g}$. The reaction ending temperature was $100{ }^{\circ} \mathrm{C}$ reached after the $1 \mathrm{~h}$ and $50 \mathrm{~min}$ preheating period. The average was $101{ }^{\circ} \mathrm{C}$; the sulfuric acid concentration was $0.45 \mathrm{M}$; the liquid-to-solid ratio of $20: 1$, i.e., the liquid phase volume was $10 \mathrm{~L}$ water and the solid material dose was $500 \mathrm{~g}$ wheat straw; the solid residue yield was $55.34 \% \mathrm{w} / \mathrm{w}$ on dry basis.

\subsection{Adsorption Tests}

The water and oil adsorbency (defined as the ratio of water or oil adsorbed to dry adsorbent weight, according to the ASTM F726-06 method, 2005) test was performed, following the procedure of this standard method as follows. The adsorbent sample to be tested was $4 \mathrm{~g}$. In the case of oil spills, a $2 \mathrm{~L}$ jar was filled with $1 \mathrm{~L}$ freshwater, seawater or substitute seawater and $50 \mathrm{~mL}$ of test liquid (diesel, crude oil). The container was then placed on a shaker table, at a frequency of 150 rpm for 2, 5, 15, 30, 60, 120, 240 and $1440 \mathrm{~min}$ and allowed to settle for a period of $2 \mathrm{~min}$ for keeping the lignocellulosic material in suspension. The various adsorption tests were conducted at $\mathrm{pH} 7.7 \pm 0.1$ as regards freshwater and $7.9 \pm 0.1$ as regards seawater. These $\mathrm{pH}$ values are comparable with the literature values which are in most cases 6-8 [22-24]. The contents of the jar are strained through a mesh basket to catch the adsorbent samples, which are then weighed after a $30 \mathrm{~s}$ drain period. In the case of the oil spill test, the water in adsorbed oil/water mixture was determined by distillation according to the ASTM D 95 method using a typical assembly with glass still. The material to be tested was heated under reflux with $100 \mathrm{~mL}$ diesel oil as solvent-carrier liquid, which was co-distilled with the water in the sample. Condensed solvent and water were continuously separated in a trap, the water was settling in the graduated section of the trap and the solvent was returning to the still. The total adsorbency is the amount of oil and water adsorbed per gram of untreated and pre-treated wheat straw. In the case of oil spills, the relative adsorbency was the fraction of oil compared to the oil/water mixture adsorbed by wheat straw. As regards diesel and crude oil spills the relative diesel adsorbency (RDA) and the relative crude oil adsorbency (RCOA) were determined, respectively.

\section{Results and Discussion}

The modelling of the adsorption process of diesel, crude oil, decane and n-dodecane on untreated and modified biomass fraction was studied. Four kinetic models examined herein: Lagergren, Second order, Intra-particle diffusion model, Elovich and Fractional. Kinetic results of the adsorption rate batch experiments, in the cases: (a) of diesel and (b) crude oil adsorption on UWS (Untreated Wheat Straw) and MWS (Modified Wheat Straw) when the oil spill is formed on seawater (i.e., Piraeus Port) were obtained. With regard to the second order kinetic model the diesel and crude oil amount adsorbed after equilibrium was also found to be higher for the MWS comparing to the UWS (Table 1) [18, 20]. 
In general the Elovich rate constant $\beta$ was significantly higher for MWS comparing to the UWS. The Elovich model gave standard error of the estimate (SEE) values relatively lower than the other kinetic models while the fractional power or power function kinetic model gave SEE values significantly lower than the Elovich model. As regards the kinetic results of decane and n- dodecane adsorption, with respect to the Lagergren kinetic model, the decane and dodecane oil amount adsorbed after equilibrium time were significantly higher for the MWS (7.18 and $5.51 \mathrm{~g} \mathrm{~g}^{-1}$, respectively) comparing to the UWS (2.78 and $2.81 \mathrm{~g} \mathrm{~g}^{-1}$, respectively). In the case of the second kinetic model, the decane and n-dodecane oil amount adsorbed after equilibrium time were also higher for the MWS (7.44 and $5.67 \mathrm{~g} \mathrm{~g} \mathrm{~g}^{-1}$, respectively) comparing to the UWS (2.94 and $2.90 \mathrm{~g} \mathrm{~g}^{-1}$, respectively). In Fig. 2, decane and n-dodecane adsorption on UWS/ MWS vs. time are presented with regard to the fractional kinetic model. The fractional power or power function kinetic model gave the lowest SEE values kinetic model in both cases.

The adsorbency of diesel, crude oil, decane and n-dodecane spills formed on various types of water was observed. The adsorbent was UWS and MWS. The crude oil adsorption on original and modified wheat straw was significantly the highest of all other adsorbates on all types of water. The effect of clay (simulating suspended solids in shoreline waters) in the case of diesel and crude oil adsorption on UWS and MWS, when the oil spill is formed on seawater (Piraeus port) and substitute seawater was found. The effect of continuous stirring (simulating sea waves), in the case of diesel and crude oil adsorption on UWS and MWS, when the oil spill is formed on seawater (i.e., Piraeus port) and substitute seawater was also investigated. The effect of chemical dispersant was studied in the cases of diesel oil and crude oil adsorption on UWS and MWS. The oil spills were formed on freshwater, sea water (Piraeus port), lake water (Koumoundourou Lake), stream water (Pikrodafnis stream) and substitute seawater.

The quality control of the stored lignocellulosic adsorbent, , may result to the constancy of the adsorptive properties of the product, determining also its partial deterioration or 'ageing', in the warehouse of the facility, where it is waiting for final usage in water pollution abatement. The constancy of ageing has been confirmed by experimental work we have performed within a 24-month period, as shown in Fig. 2. Nevertheless, the value estimated for this parameter is not the same for diesel and crude oil, being higher in the former case; on the other hand, ageing is less under simulated oil spill conditions. These results should be taken into account in the experimental design for accelerated testing [20].

Straw, an agricultural by-product, can also serve as a low-cost and relatively efficient adsorbent of various harmful compounds. In this case, adsorption of four water-soluble dyes belonging to different dye classes (specifically Bismarck brown Y, representing the azo group; methylene blue, quinone-imine group; safranin O, safranin group; and crystal violet, triphenylmethane group) on native and citric acid-NaOH-modified barley straw, both in magnetic and non-magnetic versions, was studied. The adsorption was characterized using three adsorption models, namely Langmuir, Freundlich and Sips. To compare the maximum adsorption capacities $\left(q_{\max }\right)$, the Langmuir model was employed. The $q_{\max }$ values reached 86.5-124.3 $\mathrm{mg}$ of dye per $\mathrm{g}$ of native non-magnetic straw and 410.8-520.3 $\mathrm{mg}$ of dye per $\mathrm{g}$ of magnetic chemically modified straw. Performed characterization studies suggested that the substantial increase in $q_{\max }$ values after chemical modification could be caused by rougher surface of adsorbent (observed by SEM) and by the presence of higher amounts of carboxyl groups (detected by FTIR). The adsorption processes followed the pseudo-second-order kinetic model and thermodynamic studies indicated spontaneous and endothermic adsorption. The chemical modification of barley straw led to a significant increase in maximum adsorption capacities for all tested dyes, while magnetic modification substantially facilitated the manipulation with adsorbent [25].

Table 1: Diesel and crude oil amount adsorbed on untreated (UWS) and modified wheat straw (MWS) for spills formed on five types of water.

\begin{tabular}{|l|c|c|c|c|}
\hline$q(\mathrm{~g} / \mathrm{g})$ & Diesel/UWS & Diesel/MWS & Crude oil/ UWS & Crude oil/ MWS \\
\hline Fresh Water & 2.97 & 7.25 & 3.53 & 8.02 \\
\hline Sea Water & 3.30 & 6.48 & 3.62 & 7.17 \\
\hline Substitute Water & 3.22 & 6.55 & 4.15 & 7.53 \\
\hline Stream Water & 3.40 & 6.90 & 3.92 & 8.91 \\
\hline Lake Water & 3.31 & 5.40 & 3.90 & 5.72 \\
\hline
\end{tabular}




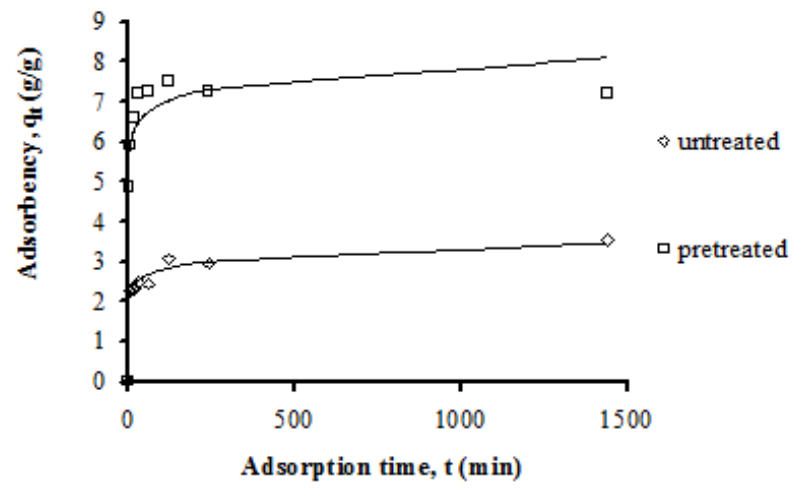

(a)

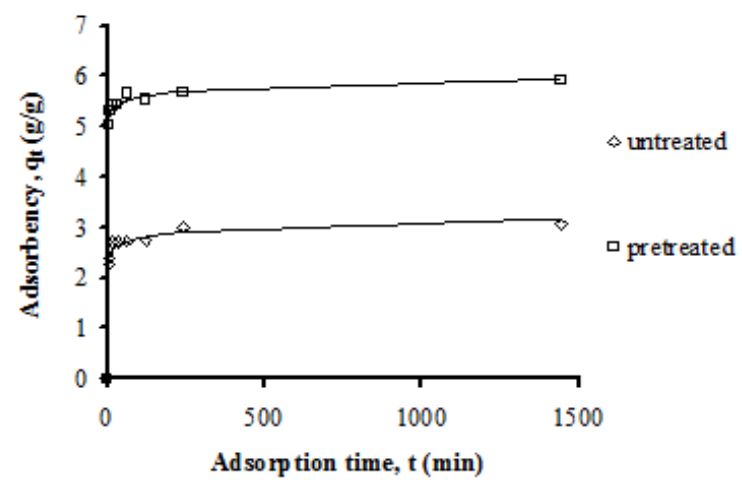

(b)

Fig. 1 Oil adsorbency for untreated and pre-treated wheat straw vs. adsorption time: for (a) decane and (b) n-dodecane; hydrocarbon spill on fresh water.

In Table 2, the water, diesel and crude oil adsorbency of untreated and modified wheat straw is compared vs. the most commonly used commercial adsorbents in the cases of (a) pure oils, (b) oil spills on freshwater and (c) oil spills on seawater. In Table 6, the oil adsorbency of the adsorbents used in this study is compared to the oil adsorbency of untreated and modified lignocellulosic adsorbents found in the recent literature.

Thereby, the adsorption capacity of modified lignocellulosic biomass is quite satisfactory, rendering this low cost material a suitable alternative of commercial materials for the removal of oil spills, dyes and heavy metals from water/wastewater effluents and aquatic environment (seas, rivers, lakes). Furthermore, the pre-treatment expenses can be covered by the co-produced sugars, raw materials suitable for the bioethanol production industry. Obviously, this process of adsorbent modification, where a wasted material is used in the management/cleaning of another waste/pollutant, may be considered to take place within an 'Industrial Ecology' framework [18]. 
Table 2: Water, diesel and crude oil adsorbency of untreated and autohydrolyzed wheat straw vs. the most commonly used commercial adsorbents in the cases of (a) pure liquids, (b) oil spills on freshwater and (c) oil spills on seawater.

\begin{tabular}{|c|c|c|c|c|c|}
\hline & & \multicolumn{4}{|c|}{ Adsorbency $\left(\mathrm{g} \mathrm{g}^{-1}\right)$} \\
\hline Oil & Sorbents & Water & Oil & Total & Relative \\
\hline \multicolumn{6}{|c|}{ (a) Pure } \\
\hline \multirow{4}{*}{$\begin{array}{l}\mathscr{Z} \\
\text { Z } \\
\text { Z }\end{array}$} & Oil adsorbent pad & 0.99 & & & \\
\hline & Oil adsorbent pom poms & 3.35 & & & \\
\hline & Untreated wheat straw & 4.89 & & & \\
\hline & Pretreated wheat straw & 11.93 & & & \\
\hline \multirow{4}{*}{ 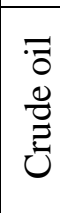 } & Oil adsorbent pad & & 12.21 & & \\
\hline & Oil adsorbent pom poms & & 5.06 & & \\
\hline & Untreated wheat straw & & 2.82 & & \\
\hline & Pretreated wheat straw & & 5.27 & & \\
\hline \multirow{4}{*}{$\begin{array}{l}\overline{\mathbb{D}} \\
\stackrel{\mathscr{D}}{0}\end{array}$} & Oil adsorbent pad & & 10.26 & & \\
\hline & Oil adsorbent pom poms & & 3.68 & & \\
\hline & Untreated wheat straw & & 2.77 & & \\
\hline & Pretreated wheat straw & & 7.15 & & \\
\hline \multicolumn{6}{|c|}{ (b) Oil spill on freshwater } \\
\hline \multirow{4}{*}{$\begin{array}{l}\bar{\sigma} \\
\bar{z} \\
\bar{E} \\
\mathcal{E}\end{array}$} & Oil adsorbent pad & 0.81 & 9.82 & 10.63 & $92.4 \%$ \\
\hline & Oil adsorbent pom poms & 0.67 & 7.77 & 8.45 & $92.0 \%$ \\
\hline & Untreated wheat straw & 1.29 & 4.36 & 5.65 & $77.1 \%$ \\
\hline & Pretreated wheat straw & 2.82 & 8.36 & 11.18 & $74.8 \%$ \\
\hline \multirow{4}{*}{$\begin{array}{l}\bar{d} \\
\stackrel{\Delta}{0} \\
\stackrel{0}{0}\end{array}$} & Oil adsorbent pad & 0.53 & 9.02 & 9.55 & $94.5 \%$ \\
\hline & Oil adsorbent pom poms & 1.41 & 4.16 & 5.57 & $74.7 \%$ \\
\hline & Untreated wheat straw & 1.68 & 3.17 & 4.86 & $65.3 \%$ \\
\hline & Pretreated wheat straw & 1.18 & 6.13 & 7.31 & $83.9 \%$ \\
\hline \multicolumn{6}{|c|}{ (c) Oil spill on seawater } \\
\hline \multirow{4}{*}{$\begin{array}{l}\overline{0} \\
\overline{0} \\
\bar{E} \\
E \\
0\end{array}$} & Oil adsorbent pad & 0.14 & 9.51 & 9.64 & $98.6 \%$ \\
\hline & Oil adsorbent pom poms & 0.28 & 7.88 & 8.16 & $96.6 \%$ \\
\hline & Untreated wheat straw & 0.94 & 4.08 & 5.02 & $81.3 \%$ \\
\hline & Pretreated wheat straw & 1.76 & 6.91 & 8.67 & $79.7 \%$ \\
\hline \multirow{4}{*}{ 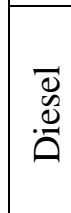 } & Oil adsorbent pad & 0.13 & 9.51 & 9.64 & $98.6 \%$ \\
\hline & Oil adsorbent pom poms & 0.28 & 5.25 & 5.53 & $94.9 \%$ \\
\hline & Untreated wheat straw & 0.88 & 2.76 & 3.64 & $75.7 \%$ \\
\hline & Pretreated wheat straw & 2.72 & 6.65 & 9.37 & $70.9 \%$ \\
\hline
\end{tabular}




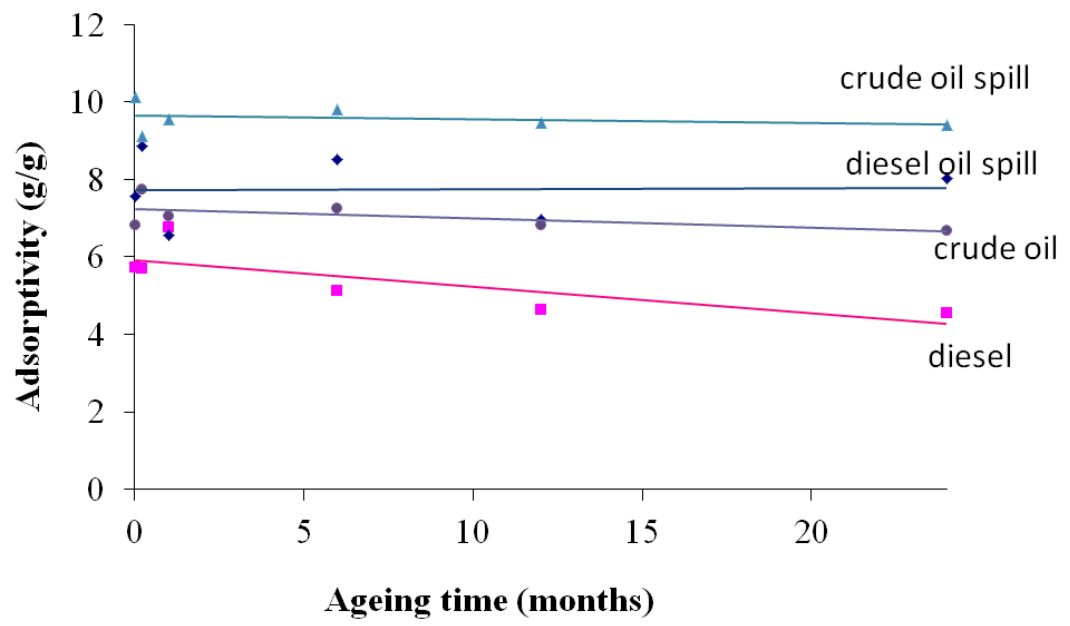

Fig. 2: Ageing within a time period of 24 months; percentage of total ageing in terms of adsorptivity loss: diesel $27.8 \%$, crude oil $7.9 \%$, diesel oil spill not-ageing, crude oil spill $2.5 \%$.

\section{Conclusion}

According to this study, modified lignocellulosic biomass (pine/spruce wood and wheat/barley straw) can be widely used for pollution cleaning (in the case of oil spills, dyes and heavy metals in aquatic environment) under the frames of biorefinery, sustainable circular bioeconomy and industrial ecology. Crude oil adsorption on original and modified wheat straw showed significantly the improved adsorbency on all types of water. All oils' adsorbencies (decane, n- dodecane, diesel and crude oil) were higher on modified wheat straw comparing to the untreated one in all oil kinds and water types. The presence of clay (simulating suspended solids in shoreline water) had negative impact in all cases of oil adsorbency on wheat straw and especially in the case of crude oil spill on seawater and substitute seawater. The effect of stirring (simulating sea waves) was positive as regards oil spill adsorbency, especially in the case of diesel and crude oil on modified wheat straw. The effect of chemical dispersant had negative impact on diesel and crude oil spills adsorbency regarding all types of water.

\section{Acknowledgements}

Financial support provided by the Research Centre of the University of Piraeus is kindly acknowledged.

\section{References}

[1] J. Ben-Iwo, V. Manovic, P. Longhurst, "Biomass resources and biofuels potential for the production of transportation fuels in Nigeria," Renew Sust Energ Rev, vol. 63, pp. 172-192, 2016.

[2] N. Scarlat, J-F. Dallemand, F. Monforti-Ferrario, V. Nita, "The role of biomass and bioenergy in a future bioeconomy: Policies and facts," Environmental Development, vol. 15, pp. 3-34, 2015.

[3] L. Staffas, M. Gustavsson, K. McCormick, "Strategies and Policies for the Bioeconomy and Bio-Based Economy: An Analysis of Official National Approaches," Sustainability, vol. 5, no. 6, pp. 2751-2769, 2013.

[4] J. E. G. van Dam, B. Klerk-Engels, P. C. Struik, R. Rabbinge, "Securing renewable resource supplies for changing market demands in a bio-based economy," Ind Crops Prod, vol. 21, no. 1, pp. 129-144, 2005.

[5] F. Cherubini, "The biorefinery concept: Using biomass instead of oil for producing energy and chemicals," Energ Convers Manage, vol. 51, no. 7, pp. 1412-1421, 2010.

[6] P. Kaparaju, M. Serrano, A-B. Thomsen, P. Kongjan, I. Angelidaki, "Bioethanol, biohydrogen and biogas production from wheat straw in a biorefinery concept," Bioresour. Technol., vol. 100, pp. 2562-2568, 2009.

[7] P. Hudman, "Energy from waste: Valorising the biorefinery concept," Renewable Energy Focus, vol. 17, no. 4, pp. 150-152, 2016.

[8] V. Menon, M. Rao, "Trends in bioconversion of lignocellulose: Biofuels, platform chemicals \& biorefinery concept," Prog. Energy Combust. Sci., vol. 38, no. 4, pp. 522-550, 2012.

[9] J. Clark, F. Deswarte, "The Biorefinery Concept: An Integrated Approach," Introduction to Chemicals from Biomass, 2nd ed., Willey, 2014. 
[10] M. Seghetta, X. Hou, S. Bastianoni, A-B. Bjerre, M. Thomsen, "Life cycle assessment of macroalgal biorefinery for the production of ethanol, proteins and fertilizers - A step towards a regenerative bioeconomy," J Clean Prod., vol. 137, pp. 1158-1169, 2016.

[11] S. Venkata Mohan, G. N. Nikhil, P. Chiranjeevi, C. Nagendranatha Reddy, M. V. Rohit, A. Naresh Kumar, Omprakash Sarkar, "Waste biorefinery models towards sustainable circular bioeconomy: Critical review and future perspectives," Bioresour. Technol., vol. 215, pp. 2-12, 2016.

[12] F. Bauer, "Narratives of biorefinery innovation for the bioeconomy - Conflict, consensus, or confusion?," Environ Innov Soc Transit. (In press)

[13] A. Zabaniotou, P. Kamaterou, V. Kachrimanidou, A. Vlysidis, A. Koutinas, "Taking a reflexive TRL3-4 approach to sustainable use of sunflower meal for the transition from a mono-process pathway to a cascade biorefinery in the context of Circular Bioeconomy," J Clean Prod., vol. 172, pp. 4119-4129, 2018.

[14] A. Zabaniotou, P. Kamaterou, A. Pavlou, C. Panayiotou, "Sustainable bioeconomy transitions: Targeting value capture by integrating pyrolysis in a winery waste biorefinery," J Clean Prod., vol. 172, pp. 3387-3397, 2018.

[15] J. Sadhukhan, E. Martinez-Hernandez, R. J. Murphy, D. K. S. Ng, M. H. Hassim, K. S. Ng, W. Y. Kin, I. F. M. Jaye, M. Y. L. P. Hang, V. Andiappan, "Role of bioenergy, biorefinery and bioeconomy in sustainable development: Strategic pathways for Malaysia," Renew Sust Energ Rev, vol. 81, no. 2, pp. 1966-1987, 2018.

[16] A. Chemodanov, A. Robin, A. Golberg, "Design of marine macroalgae photobioreactor integrated into building to support seagriculture for biorefinery and bioeconomy," Bioresour. Technol., vol. 241, pp. 1084-1093, 2017.

[17] M. Husseien, A. A. Amer, A. El-Maghraby, N. A. Taha, "Availability of barley straw application on oil spill clean up,” Int. J. Environ. Sci. Technol., vol. 6, no. 1, pp. 123-130, 2009.

[18] D. Sidiras, D. Politi, F. Batzias, N. Boukos, "Efficient removal of hexavalent chromium from aqueous solutions using autohydrolyzed Scots Pine (Pinus Sylvestris) sawdust as adsorbent," Int. J. Environ. Sci. Technol., vol. 10, no. 6, pp. 1337-1348, 2013.

[19] D. Sidiras, F. Batzias, R. Ranjan, M. Tsapatsis, "Simulation and optimization of batch autohydrolysis of wheat straw to monosaccharides and oligosaccharides," Bioresour. Technol., vol. 102, pp. 10486-10492, 2011.

[20] F. A. Batzias, D. K. Sidiras, C. G. Siontorou, A. N. Bountri, D. V. Politi, O. N. Kopsidas, I. G. Konstantinou, G. N. Katsamas, I. S. Salapa, S. P. Zervopoulou, "Experimental design for estimating parameter-values of modelling crude oil adsorption on thermo-chemically modified lignocellulosic biomass," International Journal of Arts and Sciences, vol. 7, no. 3, pp. 205-222, 2014.

[21] D. Sidiras, D. Politi, "Simulation and optimization of hexavalent chromium adsorption on autohydrolyzed Scots Pine (Pinus Sylvestris) sawdust in batch and fixed-bed systems," International Journal of Environmental Engineering, vol. 2, no. 1, p. 8187, 2015.

[22] A. Srinivasan, T. Viraraghavan, "Removal of oil by walnut shell media," Bioresour. Technol., vol. 99, no. 17, pp. 8217-8220, 2008.

[23] S. Ibrahim, S. Wang, H. M. Ang, "Removal of emulsified oil from oily wastewater using agricultural waste barley straw," Biochem. Eng. J., vol. 49, pp. 78-83, 2010.

[24] D. Angelova, I. Uzunov, S. Uzunova, A. Gigova, L. Minchev, "Kinetics of oil and oil products adsorption by carbonized rice husks," Chem. Eng. J., vol. 172, pp. 306-311, 2011.

[25] E. Baldikova, D. Politi, Z. Maderova, K. Pospiskova, D. Sidiras, M. Safarikova, I. Safarik. "Utilization of magnetically responsive cereal by-product for organic dye removal," J Sci Food Agric., vol. 96, no. 6, pp. 2204-14, 2016. 